\title{
Aglukkaq asks for US help to control oxycodone
}

$\mathrm{M}$

onths after the federal health minister ignored expert advice and approved a generic version of the much-abused prescription drug oxycodone, she has now asked for assistance from the United States in controlling the drug's use.

Federal Health Minister Leona Aglukkaq sent a letter on Mar. 12 to Gil Kerlikowske of the Office of National Drug Control Policy and Dr. Margaret Hamburg, commissioner of the US Food and Drug Administration (FDA), asking for their assistance in working together on the oxycodone (OxyContin) issue.

In the letter, Aglukkaq specifically makes reference to the dangers of the generic version of the drug she approved for manufacture in November 2012, writing that she remains "particularly concerned with the potential for abuse and diversion of pharmaceutical drugs, including generic versions of OxyContin."

"As neighbours, we have a shared responsibility to require appropriate controls in our respective jurisdictions, for the health and safety of our communities and also to reduce risks of cross-border trafficking," she states in the letter.

"Preventing the abuse and diversion of pharmaceutical drugs is an area where cooperation between our two countries would be valuable in helping to achieve our common objectives. To this end, I propose that our officials work together to develop joint evidence-based guidance on abuse deterrence that could be used on both sides of the border."

Aglukkaq made the controversial decision to approve the manufacture of generic forms of oxycodone, despite urgings from every provincial and territorial health minister to, at the very least, delay the decision until more research had been conducted.

Federal NDP Health Critic Libby Davies writes in an email that by deciding to approve generic oxycodone, "the Health Minister has abandoned another complex health issue

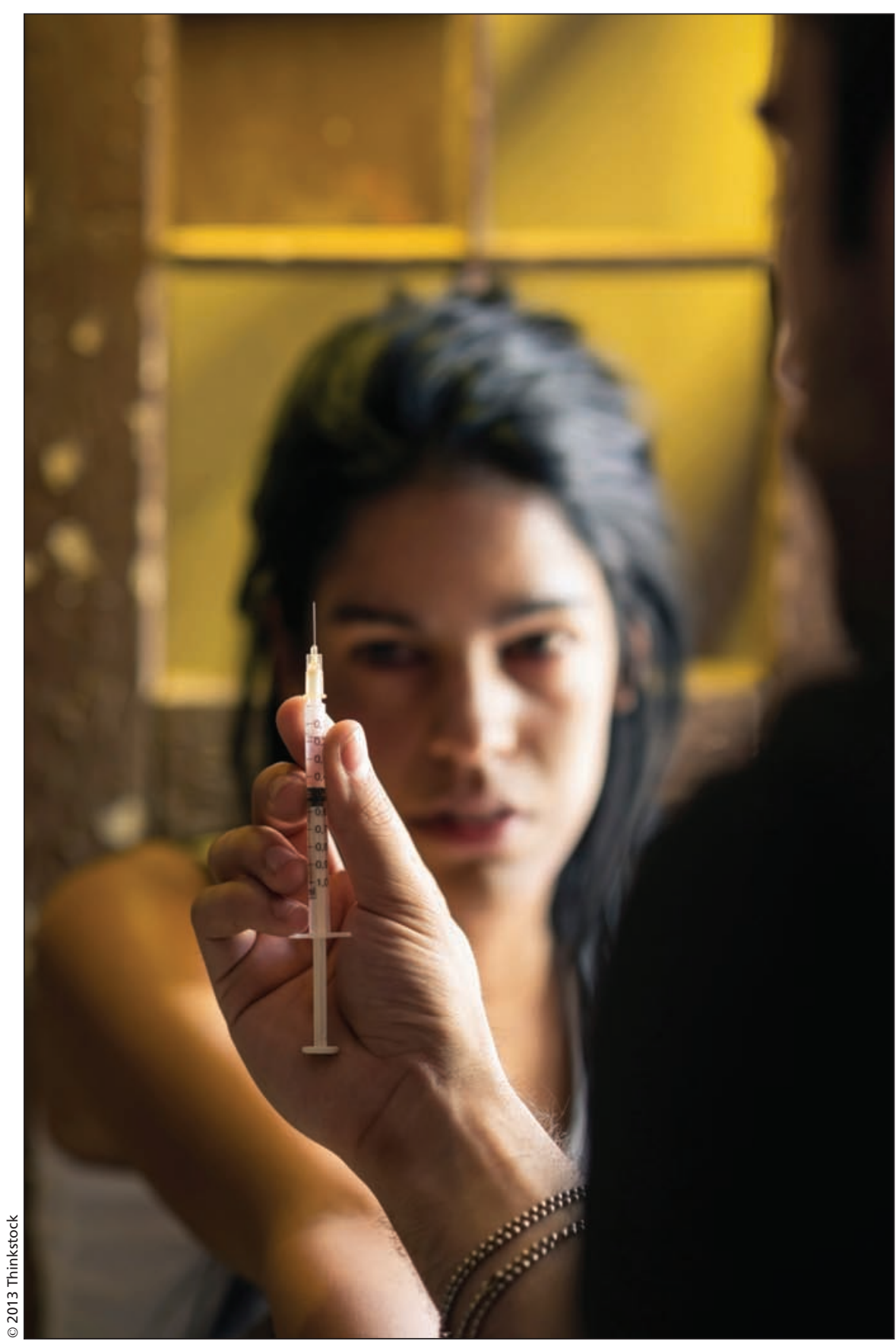

Deaths in Canada from oxycodone increased by $416 \%$ between 1999 and 2004.

and left the provinces to deal with the consequences."

"We heard the warnings from provincial ministers of health and dozens of physicians have warned that its release could gravely increase abuse of the drug, and pose a significant public health risk," Davies writes in an email.

Meanwhile, across the border, the FDA is waiting for more information on safety and effectiveness before approving new generic forms of oxycodone. 
"FDA does not intend to approve the marketing of generic versions of the original formulation of OxyContin until the agency determines whether the original formulation was withdrawn for reasons of safety or effectiveness," states FDA spokesperson Lisa Kubaska in an email.

Aglukkaq's decision to approve the generic oxycodone created waves across the border.

On Nov. 21, 2012, Montana's Attorney General at the time, Steve Bullock wrote to the minister, asking her to "respectfully reconsider" approving the manufacture of generic oxycodone. "I have concerns that allowing easier-toabuse oxycodone in Canada could undo some of the work that both Canadian and U.S. government and community leaders have accomplished in combating this epidemic," the letter stated.

That same month, the US Office of National Drug Control Policy sent out an alert regarding the increased risk of the cross-border trafficking of generic oxycodone after six generic pharmaceutical companies were licensed to manufacture the drug. "The potential exists for diversion into the United States because the old formulations, which are easier to abuse, are unavailable in the United States," the alert stated.

Canada currently ranks as the second largest consumer of prescription opioids in the world behind the US, while deaths from oxycodone increased by $416 \%$ between 1999 and 2004. Adam Miller, CMAJ

CMAJ 2013. DOI:10.1503/cmaj.109-4457 